\title{
MICRONIZED CONCRETE POWDER AS MIRCOFILLER IN CEMENT PASTE: INFLUENCE ON HYDRATION AND STRUCTURE
}

\author{
JAROSlaV TOPIČ* Z ZDENĚK PROŠEK \\ Czech Technical University in Prague, Faculty of Civil Engineering, Department of Mechanics, Thákurova \%, \\ 16629 Prague 6, Czech Republic \\ * corresponding author: jaroslav.topic@fsv.cvut.cz
}

\begin{abstract}
The reuse of old concrete as a coarse and fine recycled aggregate in cement composites is relatively well researched, and therefore a very fine fraction of recycled concrete was used in this paper. When using a very fine fraction of recycled concrete, it is appropriate to focus primarily on less technologically demanding treatment processes with minimal costs and environmental impact. Therefore this paper focus on using the fine fraction of recycled concrete as a microfiller. For this purpose, the material is treated by high-speed milling process and micronized concrete powder (MCP) is produced. Using several micronized concrete powder types that differ by origin, separation process and fineness of grinding should help understand how MCP influences the hydration process and cement paste structure. The samples with $0,10,20,30,40$ and 50 wt. \% of MCP were made to determine proper dosage in cement paste. Specific surface, matrix density and DTG analysis of micronized concrete powder were carried out. The calorimetric measurement was used to confirm how microfiller affects the hydration process. Finally, bulk density and porosity measurements were performed to determine the effect of MCP and its amount on the cement paste structure.
\end{abstract}

KEYWORDS: Cement paste, hydration process, micronized concrete powder, porosity, recycled concrete.

\section{INTRODUCTION}

The reuse of old concrete as a coarse and fine recycled aggregate in cement composites is relatively well researched. Therefore, a very fine part of recycled concrete is examined in this paper. A very fine fraction of recycled concrete is produced as waste in the production of recycled aggregate. Currently is landfilled as waste and has no further use. When we take into account that composed eligible from the cement matrix, we are talking about a production of 45 million tonnes per year within the EU [1]. Finding the application of a very fine fraction of recycled concrete in cement composites meant not only complete recycling of old concrete but also approaching the ideal circular economy [2]. When using a very fine fraction of recycled concrete, it is appropriate to focus primarily on less technologically demanding treatment processes with minimal costs and environmental impact. Due to the relatively small amount of non-hydrated clinker in the old cement matrix $[1,2]$, it seems appropriate to focus on the function of the fine fraction of recycled concrete as a microfiller. For this purpose, the material is treated by high-speed milling process and micronized concrete powder (MCP) is produced.

The use of several types of micronized concrete powder, which differ in origin, separation process, and fineness of grinding, should help understand how MCP affects the hydration process and the cement paste structure. Samples with different amounts of
MCP were made to determine the correct dosage in the cement paste.

\section{MATERIALS AND SAMPLES}

In this paper, several types of micronized concrete powder (MCP) were used. MCP-S were made of old railway sleepers. Sleepers were crushed to concrete rubble of grain size $0-16 \mathrm{~mm}$. MCP-D were made of drainage channels which were crushed to concrete rubble of grain size $0-16 \mathrm{~mm}$. MCP-CA and MCP$\mathrm{CB}$ came from old column. MCP-CA were fraction $0-1 \mathrm{~mm}$ separated after crushing. MCP-CB were made by crushing to concrete rubble of grain size 0 $16 \mathrm{~mm}$. All types of mentioned samples were milled in two steps by a high-speed electric mill.

All types of micronized concrete powder were used to preparation of cement paste samples with 0,10 , 20, 30, 40 and 50 wt. \% of MCP. All mixtures contained The Portland cement CEM I 42.5 (Radotín, Czech Republic) and had the same water/mixture ratio 0.35 . Each set contained 6 prismatic samples having dimensions of $40 \times 40 \times 160 \mathrm{~mm}$. The samples were removed from their casts after 2 days. After that, the samples were cured for 28 days in the water at the temperature of $21 \pm 2{ }^{\circ} \mathrm{C}$.

\section{Experimental METHODS}

Specific surface area and matrix density were performed by Matest E009 using the Blain method. 


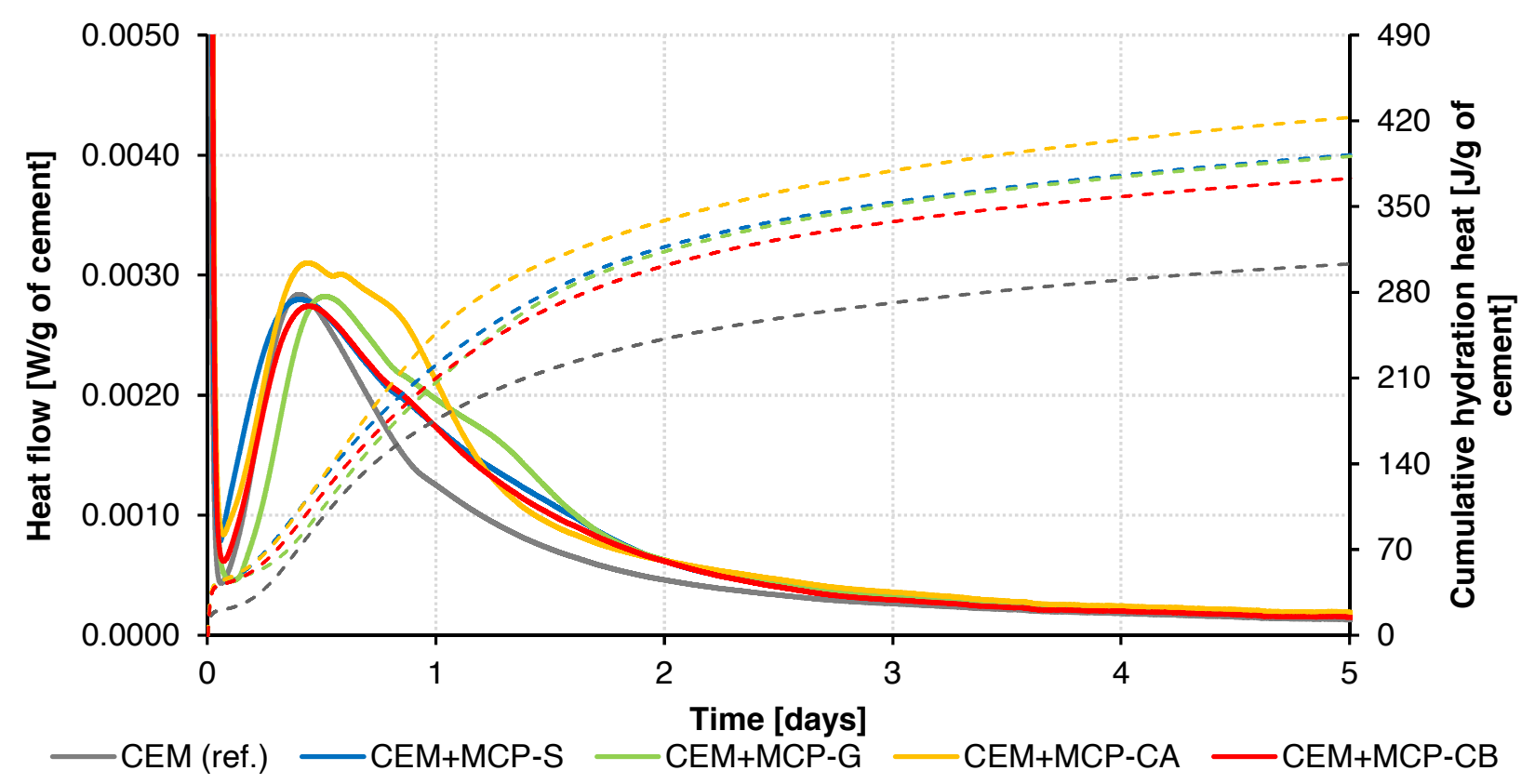

Figure 1. Curves of heat flow (solid curves) and cumulative hydration heat (dashed curves) of cement pastes during 5 days normalized to $1 \mathrm{~g}$ of cement.

\begin{tabular}{cccccc}
\hline Properties & CEM & MCP-S & MCP-D & MCP-CA & MCP-CB \\
\hline Specific surface area $\left[\mathrm{m}^{2} / \mathrm{kg}\right]$ & 380 & 265 & 324 & 860 & 177 \\
Matrix density $\left[\mathrm{kg} / \mathrm{m}^{3}\right]$ & 3105 & 2574 & 2579 & 2593 & 2600 \\
\hline
\end{tabular}

TABLE 1. Size properties of used materials.

Phases compositions were investigated by using thermogravimetric and differential thermal analysis performed by TG-DTA Setsys Evolution with spectrometer OmniStarTM. Measurements were conducted in an oxide environment with temperature range $25-1100{ }^{\circ} \mathrm{C}$.

Calorimetric measurements were performed on a TAM Air isothermal calorimeter to measure heat flux. Mixtures were tested for five days at a constant temperature of $20{ }^{\circ} \mathrm{C}$ and stored in sealable plastic containers, each containing from $25 \mathrm{~g}$ to $40 \mathrm{~g}$ of the mixture with 50 wt. \% of MCP. Based on each sample's weight (measured before testing), the results of heat flux and cumulative hydration were related to $1 \mathrm{~g}$ of cement for better detection of changes caused by different types of MCP.

The bulk density of the samples was evaluated from the dimension and weight of the prismatic samples. Total porosity was determined by using Pascal 140 and Pascal 440 device. Those two devices can detect pores with a diameter ranging from 0.00425 to $10 \mu \mathrm{m}$.

\section{Results And Discussion}

When comparing the specific surfaces, it can be seen that the MCP-CA is finely ground and is finer than cement. The MCP-D sample is slightly coarser than cement. Samples MCP-S and MCP-CB are coarser than cement. The roughest ground is the MCP-CB sample. According to Table 1, MCP-CA and MCP$\mathrm{CB}$ have the highest matrix density. This is probably due to the high content of cement matrix in MCP (table ref tab: 2) and partly due to the higher quality aggregate used in the original concrete.

TGA and DTG analysis investigated the phase compositions of micronized concrete powders. C-S-H gel $\left(\right.$ ca. $\left.100^{\circ} \mathrm{C}\right)$, portlandite $\left(\right.$ ca. $450{ }^{\circ} \mathrm{C}$ ) and $\mathrm{CaCO}_{3}$ (ca. $750{ }^{\circ} \mathrm{C}$ ) were detected [3]. The evaluation of the proportion of individual phases was performed manually from the DTG analysis curves and is evident from Table 2. It can be seen from the calculated values that MCP-CA has the highest content of C-S-H gel, while MCP-S and MCP-D have the lowest proportion of Portlandite. The evaluation shows that the origin of the material and the treatment method can have a significant effect on the ratio of individual phases in micronized concrete powder. The phase composition may be partially influenced by coincidences with other phases.

When comparing the curves of the cumulative amount of hydration heat (Figure 1), the effect of MCP on the increase in heat output is visible. All cement pastes containing MCP gave 27 to $40 \%$ more 


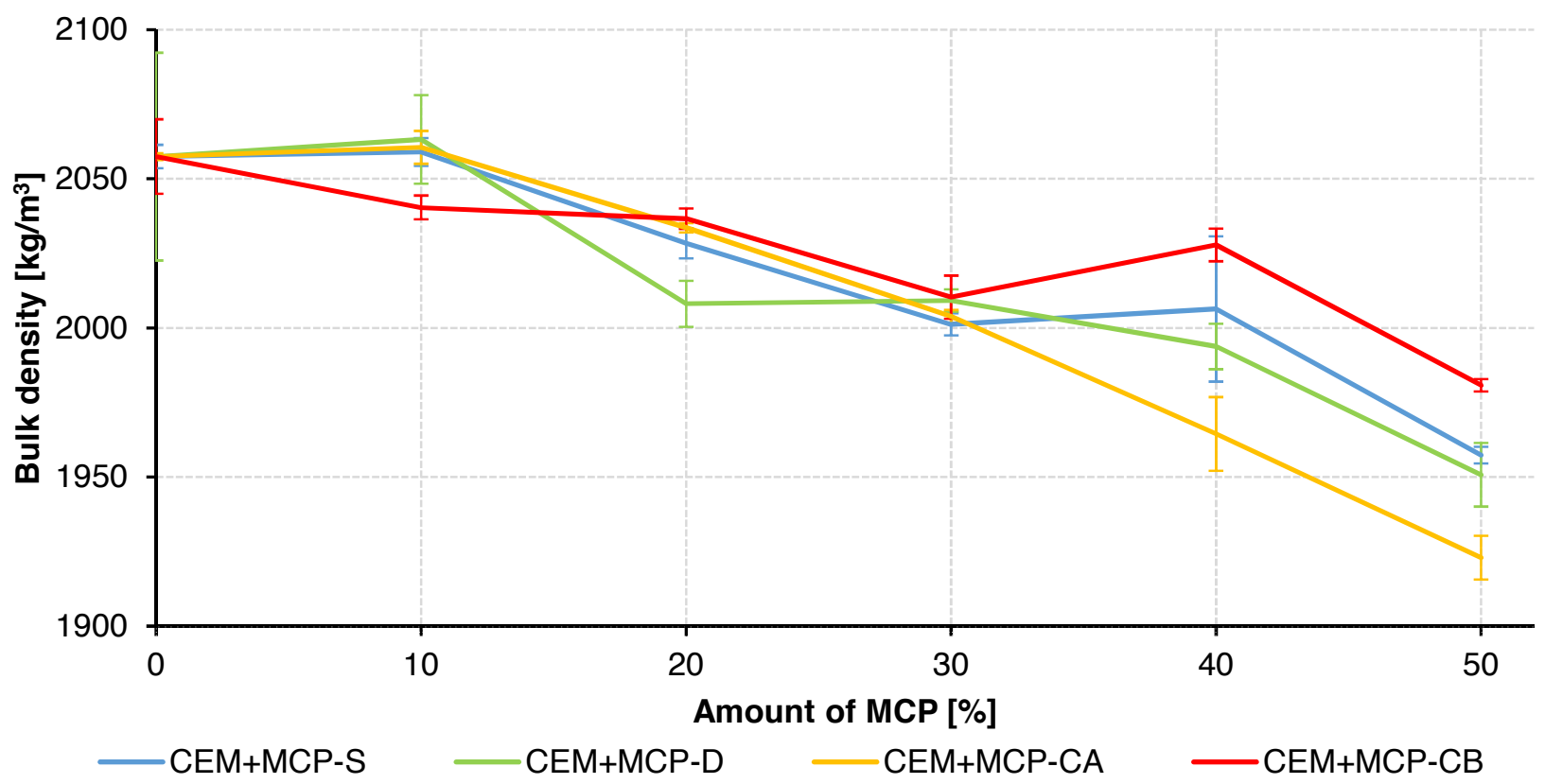

Figure 2. Dependence of bulk density of cement paste on micronized concrete powder content.

\begin{tabular}{ccccc}
\hline \multirow{2}{*}{ Phase } & \multicolumn{4}{c}{ Amount of phases by DTG [\%] } \\
& MCP-S & MCP-D & MCP-CA & MCP-CB \\
\hline C-S-H gel & 23 & 15 & 29 & 24 \\
Portlandit & 3 & 2 & 12 & 11 \\
$\mathrm{CaCO}_{3}$ & 16 & 17 & 7 & 11 \\
\hline
\end{tabular}

TABle 2. Phase composition by DTG analysis.

heat than the reference cement when hydrated after 5 days.

Calorimetric measurements and differences between individual pastes can be explained in two ways. The influence on the heat flow during hydration can be caused by residual clinker presence in the MCP and at the same time by the action of MCP as a microfiller. Given the amount of non-hydrated clinker in the MCP (below $5 \%$ ), the cumulative hydration heat emitted by pastes with MCP should be only a few percent higher. Therefore it can be assumed that the microfiller effect will cause the majority effect on the development of heat flow. Clinkers in MCP consist mainly of $\mathrm{C} 2 \mathrm{~S}$, which has a slow onset of hydration and should not significantly affect the initial phase of hydration. However, the heat flow of cement pastes with MCP is higher from the initiation phase, which supports the function of MCP as a microfiller. Higher heat flow and cumulative hydration heat of cement composites containing micronized concrete powder, which does not correspond to the reaction of residual clinkers in concrete powder (also reported by other authors [3]). Oksri-Nelfia [4] further confirms this fact by testing samples where an inert filler replaced the concrete powder. A similar verification was performed in a previous paper [5] when an inert micro- filler replaced the micronized concrete powder in the form of silica powder.

Explanation of the different kinetics when using a microfiller can be found in the work of Berodier \& Scrivener [6]. Based on a thorough analysis of calorimetric measurements and detailed examination by SEM, they explain changes in the hydration process of samples by microfillers. The microfillers were related to the increase in nucleation area for C-S$\mathrm{H}$ growth and the relatively complicated interaction mechanism of cement grains. Thanks to microfiller grains, the distance between the grains and the mutual friction of the cement grains and the microfiller during mixing is reduced. Due to mixing fraction, the layers around the dissolving surface of the cement grains are likely to be disrupted and the ions are better dispersed, resulting in more nucleation centers for $\mathrm{C}-\mathrm{S}-\mathrm{H}$ formation. At the same time, due to the friction of the cement grains and the microfiller, these nucleation centers are released and distributed on the surface of the pore system of the microfiller. They also discovered that the reduction of the grain distance is influenced by their size so that with smaller grains, the mutual distance decreases and the friction during mixing increases.

The cumulative hydration heat curves clearly show 


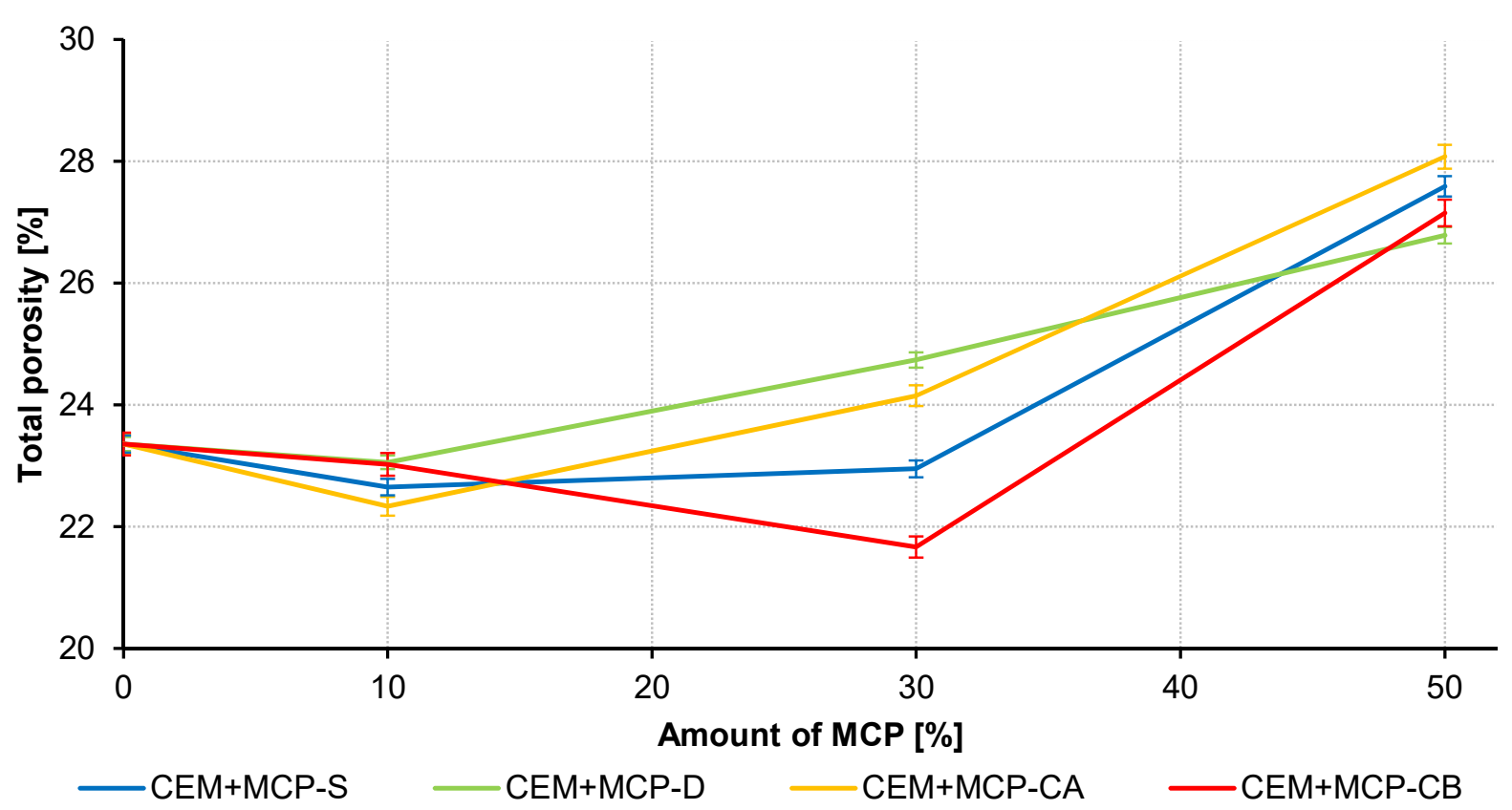

FIgURE 3. Dependence of total porosity of cement paste on micronized concrete powder content.

that the increase of hydration heat depends on higher fineness resp. smaller grain sizes of MCP. From the point of view of the Berodier \& Scrivener work [6], this is due to the decreasing distance between cement grains and microfillers. The clear increase in the heat flow of MCP-CA at the peak of the acceleration phase and the beginning of the deceleration phase by about $4 \%$ will probably be due to residual clinker presence. Due to the high fineness of MCPCA the clinkers contained were probably exposed on a higher scale compared with other types of powders and were thus better made available for further reaction.

It can be seen in Figure 2 that the bulk densities of the samples containing 10 wt. \% of MCP for most types of MCP remained the same or increased slightly. Only in the CEM+MCP-CB samples compared with the reference cement paste, there was a slight decrease in bulk density already at $10 \%$ of the MCP content, but by only $1 \%$. Further increase in the amount of MCP leads to a decrease in bulk density in most pastes. A more significant decrease than other sets can be seen in the set CEM+MCP-D at 20 wt. $\%$ of MCP. If we compare the individual sets of samples, it can be stated that up to $30 \mathrm{wt} . \%$ is a decrease very similar to about $2.5 \%$ compared to the reference cement paste. For the set of samples $\mathrm{CEM}+\mathrm{MCP}-\mathrm{CB}$ and CEM+MCP-S with the content of 40 wt. $\% \mathrm{MCP}$, there was a slight increase in bulk density compared to other samples. When comparing the bulk density of individual sets with $50 \%$ cement replacement, the smallest decrease is in the $\mathrm{CEM}+\mathrm{MCP}-\mathrm{CB}$ by less than $4 \%$ and the highest decrease is in the case of $\mathrm{CEM}+\mathrm{MCP}-\mathrm{CA}$ by less than $7 \%$ compared to the reference cement paste.

The dependence of total porosity of cement paste on the amount of MCP can be seen in Figure 3. In general, it can be said that for all sets, the addition of $10 \mathrm{wt}$. \% MCP reduces the total porosity by 0.3 to $0.7 \%$ compared to the reference cement paste. With a $30 \%$ MCP cement replacement, this trend no longer applies to all kits. For CEM+MCP-S and CEM+MCP-CB samples with 30 wt. \% of MCP, the porosity reduced by 0.4 and $1.7 \%$ compared with the reference cement paste, while the set CEM+MCP-D and $\mathrm{CEM}+\mathrm{MCP}-\mathrm{CA}$ increased porosity by 0.8 and $1.4 \%$. All samples with 50 wt. $\%$ MCP shows an increase in porosity compared to the reference cement paste. The lowest total porosity was in the CEM+MCP-D sample with 50 wt. \% MCP and the highest sample CEM+MCP-CA with 50 wt. \% MCP. Compared to the reference sample, the porosity increased by 3.4 resp. $4.7 \%$.

The reduction of cement pastes porosity with MCP under 30 wt. $\%$ is probably due to the mentioned function of MCP as a microfiller. The pores are filled with fine particles and a larger number of nucleation centers are formed and distributed, leading to better filling the pores with C-S-H gel. Replacement cement over 30 wt. \% cause that small cement ratio to the total surface area of the added MCP prevails the microfiller function of MCP and leads to an increase in the total porosity and bulk density of the cement paste. Based on results published in other papers [4, 7], the influence of residual content clinker in cement paste can be neglected due to the small amount of it.

By comparing the results of bulk density and total porosity, it can be concluded that the decrease in 
bulk density as a function of the increase in MCP is not only due to the increase in porosity. In case of MCP-CA (50 wt. \% of MCP), the porosity increased by $4.7 \%$ compared to the reference paste, but the decrease in bulk density is almost $7 \%$. Therefore, the density of the MBM matrix, which is about $16 \%$ lower than cement, also has a comparable effect on the bulk density.

In the article Šeps \& Broukalová [8], which deals with the effect of MCP on bulk density, the same trend of decreasing bulk density depending on the increasing amount of MCP is seen. Bordy, et al. [3] discusses, among other things, the effect of the amount of concrete powder on the porosity of samples. Their work shows that the porosity increases with an increasing amount of concrete powder (specific surface area similar to MCP-D). Even with small replacements, there is no apparent reduction in porosity. The difference compared to the results in Figure 3 with a small cement replacement is because they tested cement mortars and using a less accurate method.

\section{Conclusions}

This paper focuses on the influence of different types and amounts of micronized concrete powder on the hydration properties and structural properties of cement paste. In this experiment, the RCP was used to fulfills the role of micro filler. Based on the results, the following findings are summarized:

- Origin of the material and the method of treatment can significantly affect the ratio of individual phases in micronized concrete powder, which further influenced the matrix density.

- The majority effect of MCP on the development of heat flow was caused by microfiller effect. Hydration of residual clinker in MCP may be neglected due to his low amount.

- Addition of $10 \mathrm{wt}$ \% MCP reduces the total porosity by 0.3 to $0.7 \%$ compared to the reference cement paste.

- The reduction in porosity is more pronounced in samples with coarser concrete powder.

- Addition of MCP under the 30 wt. \% decrease the porosity.

\section{ACKNOWLEDGEMENTS}

The authors wish to express their gratitude for financial support to the Faculty of Civil Engineering, Czech Technical University (CTU) in Prague under SGS project No. SGS19/148/OHK1/3T/11. The authors also thanks to the Center for Nanotechnology in Civil Engineering at the Faculty of Civil Engineering, CTU in Prague.

\section{REFERENCES}

[1] E. Commission. Eurostat, 2019. [Online] Available at: https://ec.europa.eu/eurostat/data/database [Access 18 prosinec 2019].

[2] E. Commission. European commission communication com closing the loop - an eu action plan for the circular economy, 2015. [Online] Available at: https://eur-lex.europa.eu/legalcontent/EN/TXT/?uri=CELEX:52015DC0614 [Access 18 prosinec 2019].

[3] A. Bordy, A. Younsi, S. Aggoun, B. Fiorio. Cement substitution by a recycled cement paste fine: Role of the residual anhydrous clinker. Construction and Building Materials 132:1-8, 2017. DOI:10.1016/j.conbuildmat.2016.11.080.

[4] L. Oksri-Nelfia, P. Y. Mahieux, O. Amiri, et al. Reuse of recycled crushed concrete fines as mineral addition in cementitious materials. Materials and Structures/Materiaux et Constructions 49(8):32393251, 2016. DOI:10.1617/s11527-015-0716-1.

[5] J. Topič, Z. Prošek. Hydration Proceess and Mechanical Properties of Cement Paste with Recycled Concrete Powder and Silica Sand Powder. Acta Polytechnica CTU Proceedings 13:125, 2017. DOI:10.14311/app.2017.13.0125.

[6] E. Berodier, K. Scrivener. Understanding the filler effect on the nucleation and growth of C-S-H. Journal of the American Ceramic Society 97(12):3764-3773, 2014. DOI:10.1111/jace.13177.

[7] Z. Prošek, P. Tesárek, J. Trejbal, T. Horová. Recycling of construction waste using high-speed milling process: determination of waste concrete. Acta Polytechnica CTU Proceedings 22:88-93, 2019. DOI:10.14311/app.2019.22.0088.

[8] K. Šeps, I. Broukalová. Properties of cement based composite with fine ground recycled concrete. In Advanced Materials Research, vol. 1000, pp. 110-113. Trans Tech Publ, 2014. DOI:10.4028/www.scientific.net/AMR.1000.110. 